\title{
A Novel Mining Method for Longwall Panel Face Passing through Parallel Abandoned Roadways
}

\author{
Yang Li, Yuqi Ren (D), Nan Wang, Junbo Luo, Na Li, Yikun Liu, and Guoshuai Li \\ School of Energy and Mining Engineering, China University of Mining and Technology (Beijing), Beijing 100083, China \\ Correspondence should be addressed to Yuqi Ren; ryq2019cumtb@126.com
}

Received 27 March 2021; Accepted 29 May 2021; Published 15 June 2021

Academic Editor: Xiaowei Feng

Copyright (c) 2021 Yang Li et al. This is an open access article distributed under the Creative Commons Attribution License, which permits unrestricted use, distribution, and reproduction in any medium, provided the original work is properly cited.

\begin{abstract}
Mining pressure behavior in the process of longwall panel face passing through the parallel abandoned roadways (PARs) is different from the ordinary longwall panel face. It is easy to induce the accident of roof falling, coal wall spalling, and crush accident of shield. In order to reduce the occurrence of mine pressure accidents and ensure safe mining, a new mining method named "swing-inclined" mining method was proposed and was employed in the E13103 of Cuijiazhai coal mine. Based on the process of the longwall panel face passing through the PARs, a long-span and multisupport mass-structure model of the roof was established. The maximum support capacity of shield was calculated combined with stability relation between "roof-shield-PAR'similar pillar (SP)'-coal wall." It provided the basis for determining the reasonable support capacity of shield. Moreover, the sensitivity analysis of influenced factors to the maximum support capacity of shield was carried out by using Matlab software. The sensitivity analysis results indicated that different factors had a different effect on the support capacity of shield. And, the process of passing through the PARs can be divided into 3 stages, depending on the relation between support capacity of shield and width of SP. In different stages, the change degree of support capacity of shield was different. The support capacity of shield is mainly influenced by the hanging distance of the main roof and the horizontal distance between the support point of the coal wall and the breaking position of the main roof. By on-site measurement, the sensitivity analysis results were verified.
\end{abstract}

\section{Introduction}

In China, due to the disorder and over boundary mining of small coal mines, many anfractuous abandoned roadways (ARs) were left in coal seams [1-5]. A large danger of safety and efficiency would happen when the longwall mining panel face passes through the ARs. Therefore, the roof strata control is a key problem for longwall mining panel face to pass through the ARs due to the existence of ARs [6-10]. However, the roof strata control is related to the relation between the shield and roof in the panel face. At the same time, the roof strata control in the panel face plays an important role in safe mining. The roof strata control is related to the width of the ARs, the caving space of the ARs, and the angle between the ARs and the panel face. When the angle between the abandoned roadway and the panel face is $0^{\circ}$, the abandoned roadway (AR) is named parallel abandoned roadway (PAR). The roof is easy to cut off in front of the shield in the panel face when the AR is parallel to the panel face because the span of the roof is too large. And, the crushing accident of the shield in panel face happens more easily.

In recent years, many scholars had established the breaking model of the roof strata in the longwall mining panel face and studied the relation between the shield and roof strata in the longwall mining panel face [11-15]. Zhang et al. studied the fracture behaviors of the roof strata due to the existence of ARs and examined the roof failure characteristics, forces acting on shields, and action characteristics of abutment stress when the panel face passed through the ARs [16]. Liu et al. established a mechanical breaking model of the main roof in the mining process of passing the ARs. Three factors were put forward which influenced the breaking position of the main roof [17]. Liu et al. studied the mechanism of the advanced presplit of the main roof using physical simulation, which was useful to 
prevent the occurrence of advanced fracture in the panel face [18]. Du proposed a new technology named "waiting pressure and stop-mining" before the panel face passed through the AR and determined the key relevant parameters of the technology in the Halagou coal mine [19]. Xie et al. analyzed technical difficulties of "shield and surrounding rock" control when passing through the AR in a fully mechanized panel face and proposed a new integrated control technique. Meanwhile, a structure model of the main roof during passing through the AR was established and critical resistance of shield under long key block was obtained [20]. Xu et al. revealed the stability mechanism of the main roof of AR by establishing a mechanical model and analyzed the major reasons for the crushing accident of shield [21].

In summary, most studies on the passing through the ARs of longwall mining panel face only focus more on increasing the support capacity of shield to ensure safe mining rather than considering the shield-roof relation between the shield and the roof $[22,23]$, which also means the shield-roof relation is ignored. Therefore, how to increase the support capacity of shield reasonable is worth studying to ensure the longwall panel face passes through PARs safely [24].

In this paper, a new mining method named the "swinginclined" mining method to pass through the PARs was proposed to ensure safe mining. At the same time, the shieldroof relation was studied under the condition of employing the new mining method to pass through the PARs. The reasonable support capacity of shield was calculated by establishing a long-span and multisupport mass-structuremodel of the roof when the panel face passed through the PARs. Moreover, Matlab software was used to carry out the sensitivity analysis of influence factors to the support capacity of shield when the longwall panel face passed through the PARs. Besides, some feasible method was introduced to reduce and determine the support capacity of shield. Finally, the conclusion of the sensitivity analysis was verified by onsite measurement.

\section{Case Study}

The average buried depth of the coal seam of the E13103 panel in the Cuijiazhai coal mine is about $337 \mathrm{~m}$. And, the average thickness and the average dip angle are $4.24 \mathrm{~m}$ and $7^{\circ}$, respectively. The roof and the floor of the E13103 panel include siltstone, claystone, and limestone.

As shown in Figure 1, there are many crisscross ARs in the two adjacent panels. According to the angle between the ARs and the panel face, the ARs are divided into 3 forms, which are oblique ARs (OAR), vertical ARs (VAR), and parallel ARs (PAR) [25-27]. When the panel face excavates to the OARs and VARs, there is little influence on mining. So, some special methods are taken to prevent roof falling and coal wall spalling.

However, there are four PARs in the E13103 panel and the E13105 panel with $2 \sim 4 \mathrm{~m}$ width and $2 \sim 3 \mathrm{~m}$ height. And, the original width and height are $3.5 \mathrm{~m}$ and $4 \mathrm{~m}$, respectively, which means the four PARs are all excavated along the roof of coal seam. Besides, all of the PARs are supported by wood cribs, as shown in Figure 2(a). And, some of the PARs are seriously deformed with the width and the height less than $2 \mathrm{~m}$, even disappeared. When the panel face passes through the PARs, there is much influence on mining with the roof falling and the crushing accident of shield, as shown in Figure 2(b). The reason is that the contacting space is large and even fully contacting in the whole mining process [28]. This causes the panel face to stagnate for nearly 20 days.

\section{New Mining Method}

When the panel face passes through the PARs, many serious damaged forms occur because the damaged area is large. At the same time, the damaged forms are difficult to deal with. The process of the panel face passing through the PARs is equivalent to excavate the pillar between the PARs and the panel face. According to [13], the pillar between the PAR and the panel face is deemed as a "similar pillar" (SP), which also means the process that the panel face passes through the PARs is equivalent to the process of recovering SP $[29,30]$. When the panel face passes through the PARs, the width of SP gradually reduces to $0 \mathrm{~m}$ and the strength of SP also decreases. In other words, when the load on the SP reaches the ultimate strength, the SP becomes the yield pillar with the elastic state to the plastic state. Because the exposed area of the PAR is large, it is easy to cause the roof to fall in the panel face. So, a new mining method named the "swing-inclined" is put forward. The new mining method can reduce the exposed area and prevent the scraper conveyor from jumping up and down under the condition that the altitude of the headgate is much higher than the tailgate. The "swing-inclined" mining method is a process of swinging forward mining. First, the end of the shear is ahead of the panel face before the panel face passes through the PARs. Then, the head of the shear is ahead of the panel face when the panel face passes through the PARs.

The "swing-inclined" mining method prevents the instability of the scraper conveyor in the panel face. The procedure of the "swing-inclined" mining method is as follows:

(1) The end of the shear begins to incline at a distance of $30 \mathrm{~m}$ from the PAR. The head and the end of shears and scrapers both keep advancing. At this time, the end of the shear is $1 \sim 2$ more cuts than the head, as shown in Figure 3(a).

(2) When the end of the shear is $6 \mathrm{~m}$ more advanced than the head of the shear, the end of shears adds scrapers to meet the length of the inclined panel face, as the red scrapers shown in Figure 3(b). Then, they both keep advancing.

(3) When the head of the shear is $9 \mathrm{~m}$ more advanced than the end of shear, the head of the shears adds scrapers, as the pink scrapers shown in Figure 3(c). And, at this time, the panel face passes through the 


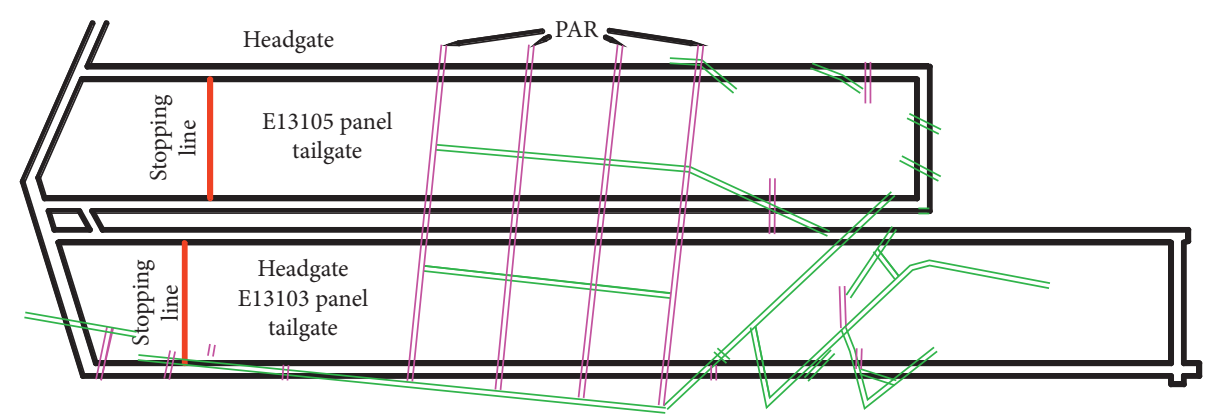

FIgURe 1: Panel layout for ARs in E13103 and E13105.

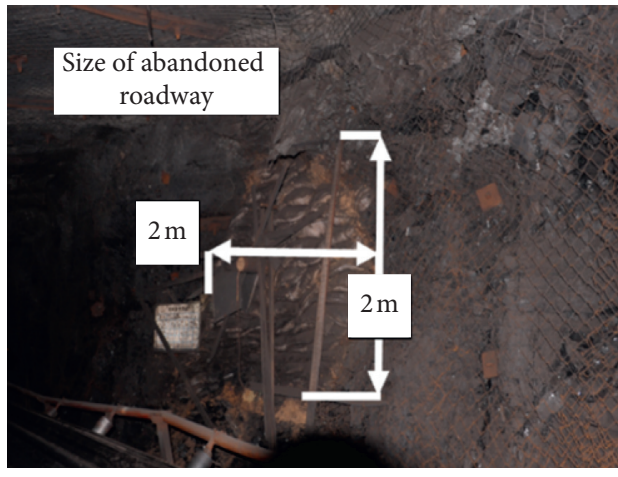

(a)

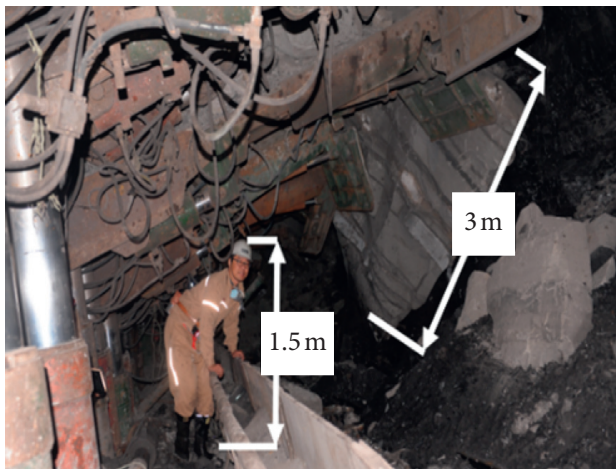

(b)

Figure 2: Situation of ARs on site. (a) Support form of AR. (b) Roof fall in the AR.

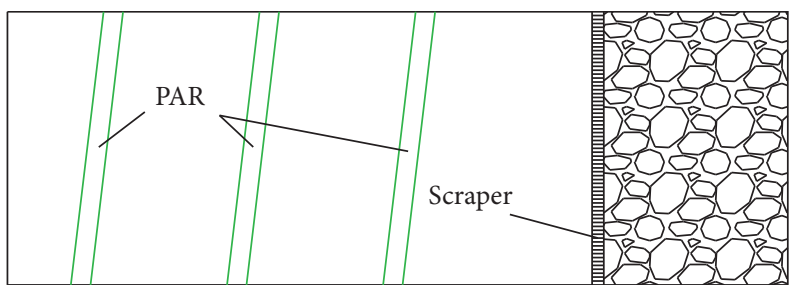

(a)

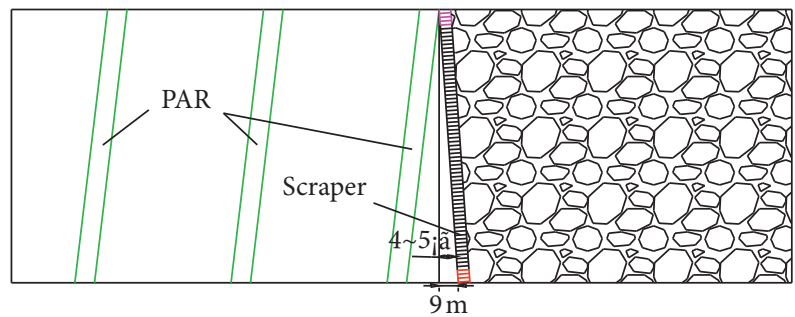

(c)

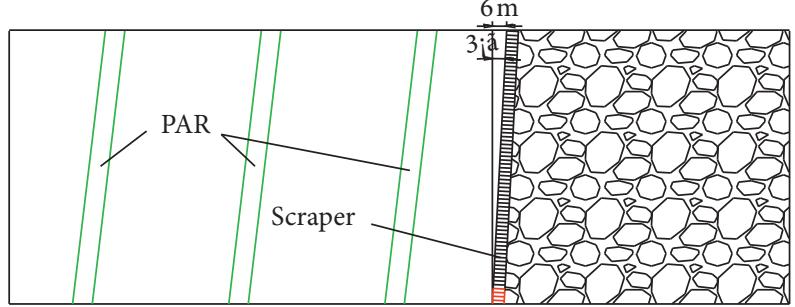

(b)

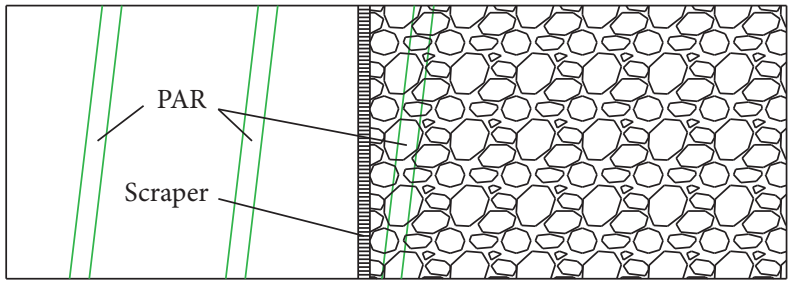

(d)

FIgUre 3: Passing through the PAR. (a) Advancing of the head and the end of shears and scrapers. (b) Adding scrapers and shears in the end of panel. (c) Adding scrapers and shears in the head of panel. (d) End of "swing-inclined" mining. 
PAR with an angle of $4 \sim 5^{\circ}$ between the panel face and the PAR.

(4) After passing through the PAR, the face begins to correct like the initial state, as shown in Figure 3(d).

\section{Calculation for Support Capacity of Shield}

The shield-roof relation is the foundation of ground control in the stope and the basis to verify the effect of roof stability and support design [31]. For the E13103 panel, the shieldroof relation becomes more complicated due to the existence of PARs. So, it is necessary to study the stable relation among the "roof-shield-PAR-SP-coal wall" when the panel face passes through the PARs.

According to the practical situation in the E13103 panel, when the distance between the panel face and the PAR is more than $13 \mathrm{~m}$, the SP is stable and has great supporting capacity. However, when the width of the pillar decreases with the advancement of the panel face, the SP changes from an elastic state to a plastic state. The SP is unstable and the supporting capacity also decreases. At the same time, it is necessary to take some effective measures to improve the support capacity to roof. So, the critical width of the SP is $13 \mathrm{~m}$. When the distance between the panel face and the PAR is less than $13 \mathrm{~m}$, the SP is in a plastic state and loses stability. When the distance is $10 \mathrm{~m}$, the vertical stress is maximum on the pillar. When the distance is less than $10 \mathrm{~m}$, the SP gradually loses stability. The pressure of the roof transfers to the position between the coal wall and support. And, it is necessary to do a good job to prevent the roof from falling and coal wall spalling in the face.

From the above discussion, the critical width of the SP is $13 \mathrm{~m}$. And, when the distance between the panel face and the PAR is more than $13 \mathrm{~m}$, the period weighting of the main roof is not influenced by the existence of PAR. Therefore, the process of passing through PAR with a distance of $13 \mathrm{~m}$ between the panel face and the PAR is defined.

From Figure 4, the cantilever length of the main roof increases suddenly because the strength of the SP decreases with losing stability. And, the abutment pressure in the coal wall increases due to the existence of the PAR. The broken position of the main roof moves forward to the other side of the PAR. So, the breaking of main roof forms is a long-span and multisupport mass-structure-model, as shown in Figure 4(a). It includes a long-span rock block B across the SP and the PAR. which is supported by the coal wall, the shield in the panel face, the residual strength of coal, and the articulated rock block C. When the strength of the SP decreases to 0 , the support load of shield is the maximum. The force analysis of the breaking structure of the main roof is shown in Figure 4(b). If the deflection of the rock block is not considered, the breaking structure of the main roof is shown in Figure 4(c).

Block B is cracked at point $D$ under the function of the structural force in the period weighting. The sum of the moment around point $D$ is 0 for block $B$, as shown in Figure 4(c):

$$
\begin{aligned}
\sum M_{D}= & 0, \\
M_{D}= & P\left(L_{B}-L_{B} \sin \alpha\right)+F_{T} L_{1}+F_{N} L_{2}+F_{M} L_{3} \\
& -\frac{1}{2}\left(G_{B}+Q_{B}\right) L_{B} \cos \alpha=0, \\
L_{B}= & L_{2}+L_{e}+L_{m}+L_{x}, \\
F_{M}= & P_{M}-G_{M}, \\
L_{3}= & L_{2}+L_{e}+\frac{L_{m}}{2},
\end{aligned}
$$

where $F_{T}$ is the support force of shield to block $\mathrm{B}, \mathrm{kN}, L_{B}$ is the length of block $\mathrm{B}, m, L_{2}$ is the horizontal distance between the support point of the coal wall and the breaking position of the main roof, $m, L_{e}$ is the width of PAR, $m, L_{m}$ is the width of SP, $m, L x$ is the hanging distance of the main roof, $m, L_{1}$ is the horizontal distance between the support point of shield and the breaking position of the main roof, $m, L_{3}$ is the horizontal distance between the center support point of SP and the breaking position of the main roof, $m, F_{M}$ is the support force of the SP to block $\mathrm{B}, \mathrm{kN}, P_{M}$ is the residual load of SP, $\mathrm{kN}, G_{M}$ is the weight of the immediate roof, $\mathrm{kN}, F_{N}$ is the support force of the coal wall to block $\mathrm{B}, \mathrm{kN}, G_{B}$ is the weight of block $\mathrm{B}, \mathrm{kN}$, and $Q_{B}$ is the uniform load on block $\mathrm{B}$, $\mathrm{kN}$.

In order to ensure the stability of block $B$, the premise is that the sum of vertical shear is less than friction between the adjacent blocks, that is,

$$
P \tan \varphi \geq\left(G_{B}+Q_{B}\right)-F_{T}-F_{M}-F_{N} .
$$

The maximum support capacity of shield $\left(P_{T}\right)$ is obtained from formulas (2) and (6), and it is

$$
P_{T}=F_{T}+G_{T}=\frac{\left(G_{B}+Q_{B}\right)[1-\sin \alpha \tan \varphi / 2(1-\sin \alpha)]-\tan \varphi\left(F_{N} L_{2}+F_{M} L_{3}\right) / L_{B}(1-\sin \alpha)}{\left[1-\tan \varphi L_{1} / L_{B}(1-\sin \alpha)\right]}+\gamma_{i m} h_{i m} L_{S}
$$

where $G_{T}$ is the gravity of the immediate roof, $\mathrm{kN} / \mathrm{m}, L_{S}$ is the average overhang distance of immediate roof above the shield, $m, \gamma_{\mathrm{im}}$ is the density of immediate roof, $m, h_{\mathrm{im}}$ is the thickness of immediate roof, $m, \tan \varphi$ is the friction coefficient, also named $f$, and $\alpha$ is the rotation angle of block $\mathrm{C}$, .
According to the investigation of the field engineering, $G_{B}=34.5 \mathrm{kPa}, Q_{\mathrm{B}}=34.5 \mathrm{kPa}, \alpha=5^{\circ}$, and $\varphi=30^{\circ}$. Based on the quantitative relationship among the different lengths with characteristics of dynamic change, some main length are determined in every sensitivity analysis of each relationship. 


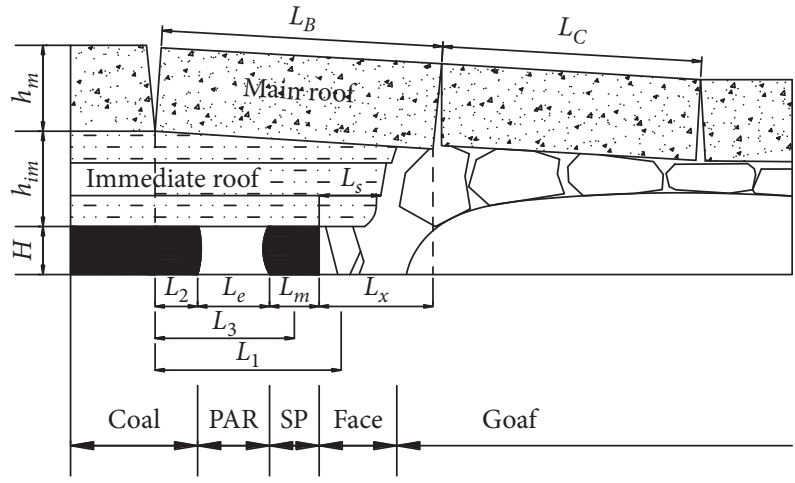

(a)

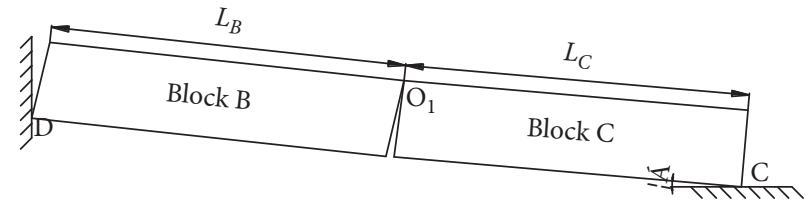

(b)

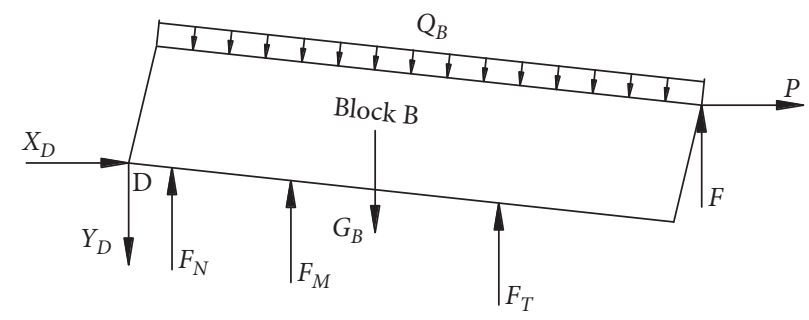

(c)

Figure 4: Structural model.

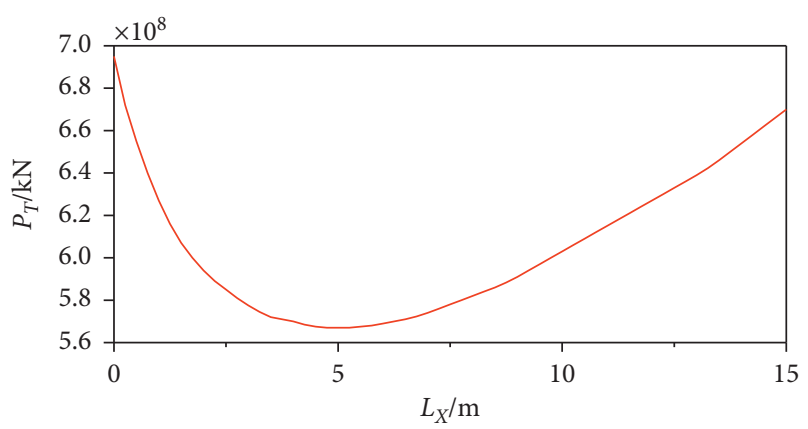

Figure 5: Relation between $P_{T}$ and $L_{X}$.

\section{Sensitivity Analysis and Discussion}

5.1. Hanging Distance of Main Roof $\left(L_{X}\right)$. Figure 5 shows the relation between the support capacity of shield $\left(P_{T}\right)$ and the hanging distance of the main roof $\left(L_{X}\right)$ when $L_{2}=3 \mathrm{~m}$, $L_{\mathrm{m}}=5 \mathrm{~m}$, and $L_{\mathrm{e}}=3 \mathrm{~m}$. As shown in Figure 5, the support capacity of shield decreases first and then increases with the $L_{X}$ increasing. When the hanging distance of the main roof is $0 \mathrm{~m}$, that is, the breaking position is at the top of the shield, the value of support capacity of shield is maximum. The reason is that the breaking compression impact of block $\mathrm{B}$ and the gravity of block $\mathrm{C}$ are superposition at this position. When the hanging distance of the main roof is $4 \sim 5 \mathrm{~m}$, the value of support capacity of shield is minimum. Because the length and weight of block $\mathrm{C}$ on the shield decreases with the hanging of the main roof increases. At the same, there is a horizontal extrusion pressure between block $\mathrm{C}$ and block $\mathrm{B}$, which causes the load of block $C$ to support capacity of shield to decrease. So, the support capacity of shield rapidly decreases. After that, the support capacity of shield increases because block $B$ is getting into a long-span beam with increase of the hanging distance of the main roof and the weight of block B applied on the shield.

5.2. Width of $S P\left(L_{m}\right)$. Figure 6 shows the relation between the support capacity of shield $\left(P_{T}\right)$ and the width of the SP $\left(L_{m}\right)$ when $L_{2}=3 \mathrm{~m}, L_{X}=15 \mathrm{~m}$, and $L_{e}=3 \mathrm{~m}$. When the width of the SP is more than $13 \mathrm{~m}$, that is, the distance between the panel face and the PAR is more than $13 \mathrm{~m}$, the breaking position of the main roof is not influenced by the existence of the PAR. So, it is defined as the process of passing through PAR within $13 \mathrm{~m}$.

As Figure 6 shown, the process of passing through the PAR can be divided into 3 stages:

(1) Stage I $\left(L_{m}=13 \sim 10 \mathrm{~m}\right)$ : in this stage, the support capacity of shield decreases with the width of SP decreasing. The SP gets into a plastic state and gradually yields. With the width of SP decreasing, the support capacity of shield also decreases, but the vertical stress of the SP increases. When the width of the SP is $10 \mathrm{~m}$, the breaking length of the main roof is $30 \mathrm{~m}$. The shield is in the stress-relaxation area and the SP is in the stress-concentration area under the main roof. So, the vertical stress of SP reaches the maximum value. At the seam time, the load of the SP is maximum and the support capacity of shield is minimum.

(2) Stage II $\left(L_{m}=10 \sim 6 \mathrm{~m}\right.$ : in this stage, the support capacity of shield increases with the width of SP decreasing. The bearing capacity of the SP decreases 


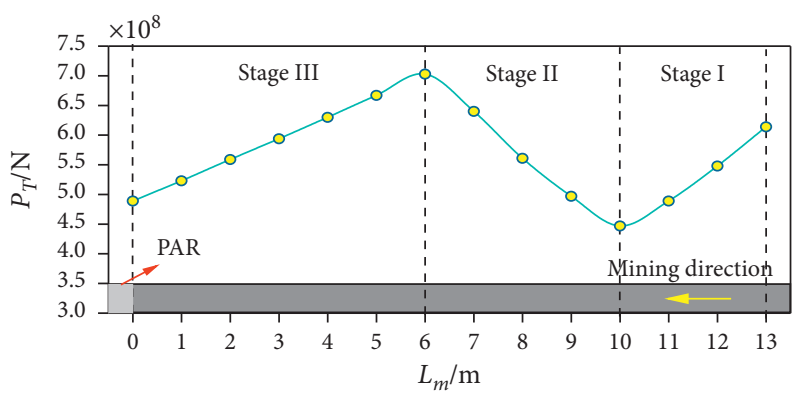

FIgUre 6: Variation of $P_{\mathrm{T}}$ passing through PAR.

and the SP tends to residual strength. When the width of the SP is $6 \mathrm{~m}$, the SP gets limited residual strength and even loses the support capacity. The support capacity of shield also gets the peak value. And, the shield is far away from point $D$ (as shown in Figure $4(\mathrm{c})$ ), and the SP is completely plastic without residual stress.

(3) Stage III $\left(L_{m}=6 \sim 0 \mathrm{~m}\right)$ : in this stage, more and more gangues are accumulated in goaf. So, the support of the gangues to the main roof increases. And, the support capacity of shield decreases with the decrease in width of SP.

5.3. Width of PAR $\left(L_{e}\right)$. Figure 7 shows the relation between the support capacity of shield $\left(P_{T}\right)$ and the width of PAR $\left(L_{e}\right)$ with different widths of SP $\left(L_{m}\right)$ in different stages when $L_{2}=3 \mathrm{~m}$ and $L_{X}=15 \mathrm{~m}$.

From Figure 7, the support capacity of shield increases linearly with the width of PAR increasing in different stages. However, the increasing rates are different in different stages. In Stages I and III of passing through the PAR, the width of PAR has a large influence on the support capacity of shield. However, the width of PAR has less influence on the support capacity of shield in stage II. So, the increasing rates in stages I and III are large than those in stage II.

In Stage, I, the maximum support capacity of shield is $6500 \mathrm{kN}$ when the width of SP $\left(L_{m}\right)$ is $13 \mathrm{~m}$ and the width of $\mathrm{PAR}$ is $5 \mathrm{~m}$. However, combining with the engineering practice with $L_{m}=13 \mathrm{~m}$ and $L_{e}=2 \mathrm{~m}$, the maximum support capacity of shield is $6000 \mathrm{kN}$. Similarly, the maximum support capacity of shield is $7000 \mathrm{kN}$ and $7700 \mathrm{kN}$ in Stage II $\left(L_{m}=7 \mathrm{~m}\right.$ and $\left.L_{e}=5 \mathrm{~m}\right)$ and Stage III $\left(L_{m}=6 \mathrm{~m}\right.$ and $L_{e}=5 \mathrm{~m}$ ), respectively. And, combining with the engineering practice with $L_{e}=2 \mathrm{~m}$, the maximum support capacity of shield is $6100 \mathrm{kN}$ and $6700 \mathrm{kN}$, respectively.

\subsection{Horizontal Distance between the Support Point of the Coal} Wall and the Breaking Position of the Main Roof $\left(L_{2}\right)$. Figure 8 shows the relation between the support capacity of shield $\left(P_{T}\right)$ and the horizontal distance between the support point of the coal wall and the breaking position of the main roof $\left(L_{2}\right)$ when $L_{m}=5 \mathrm{~m}, L_{X}=15 \mathrm{~m}$, and $L_{e}=3 \mathrm{~m}$. The support capacity of shield increases with the horizontal distance between the support point of the coal wall and the breaking position of the main roof increasing. The SP is completely at a plastic state without supporting force, and the coal wall is also at a plastic state. However, the support capacity of shield is larger because the moment of the coal wall at point D (as shown in Figure 4(c)) is small and the moment of shield at point D (as shown in Figure 4(c)) is large.

\section{Discussion}

According to the sensitivity analysis results, the hanging distance of the main roof should be $5 \mathrm{~m}$ in order to let the support capacity of shield be as small as possible. By controlling the hanging distance of the main roof, the accidents of the longwall panel face passing through the PARs reduce, which ensures normal, safe, and efficient mining. Besides, the process of the longwall mining passing through the PARs can be divided into 3 stages with the width of the SP, so the maximum support capacity of shield should be less than $7000 \mathrm{kN}$. At the same time, the horizontal distance between the support point of the coal wall and the breaking position of the main roof $\left(L_{2}\right)$ also affects the support capacity of shield. It is better to reduce $L_{2}$. Therefore, the key to choose reasonable support capacity of shield is to control the breaking length of the main roof. At present, the effective control method of the breaking length of the main roof includes the relief pressure by predrilling, hydraulic prefracturing, and deep preblasting [32-34]. By using the above control method, the mining pressure behavior will also be effectively controlled, which also means that the crushing accident of shield will be reduced and the support capacity of shield does not need to be increased without basis.

\section{On-Site Measurement}

In order to investigate the research results of sensitivity analysis, the support capacity of shield was statistically analyzed when the panel face passed through the first three PARs at the E13103 panel in the Cuijiazhai coal mine. The support capacity of No. 15 shield is shown in Table 1 and Figure 9. As shown in Table 1, the support capacity of No. 15 shield first decreases, then increases, and then decreases with the width of SP decreasing. From that, the results of field monitoring are similar to the part of 5.2, and the process of passing through the PARs can be divided into 3 stages. And, 


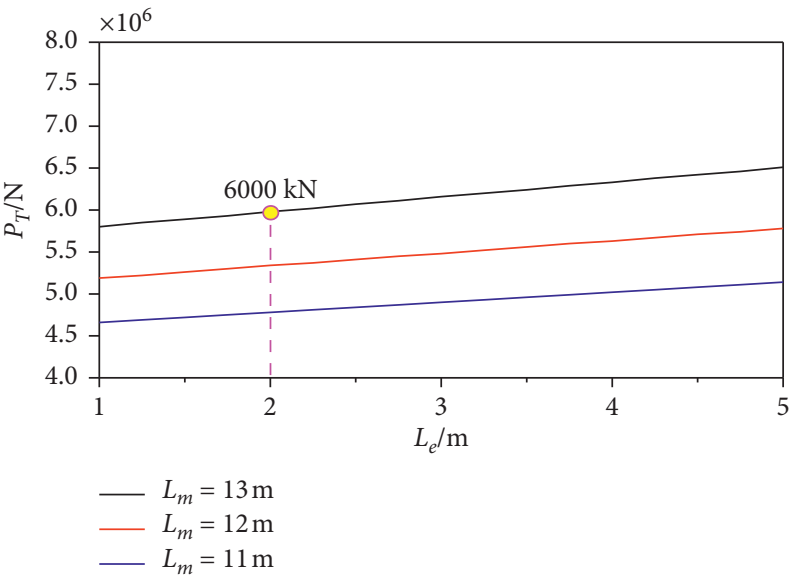

(a)

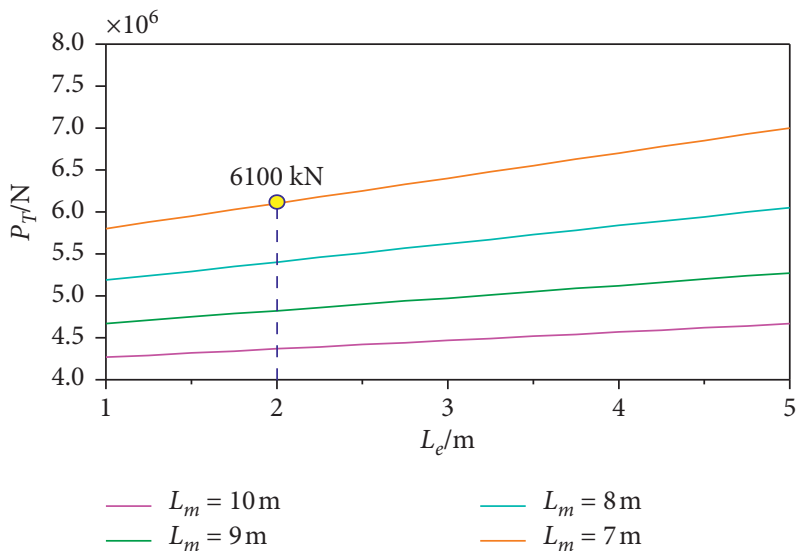

(b)

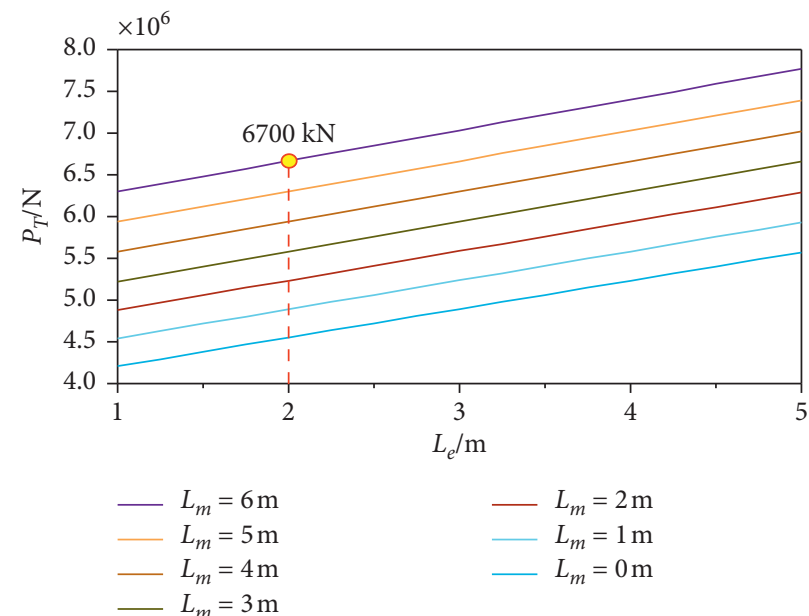

(c)

Figure 7: Relation between $P_{T}$ and $L_{m}$ with different $L_{e}$ in different stages. (a) Stage I; (b) Stage II; (c) Stage III.

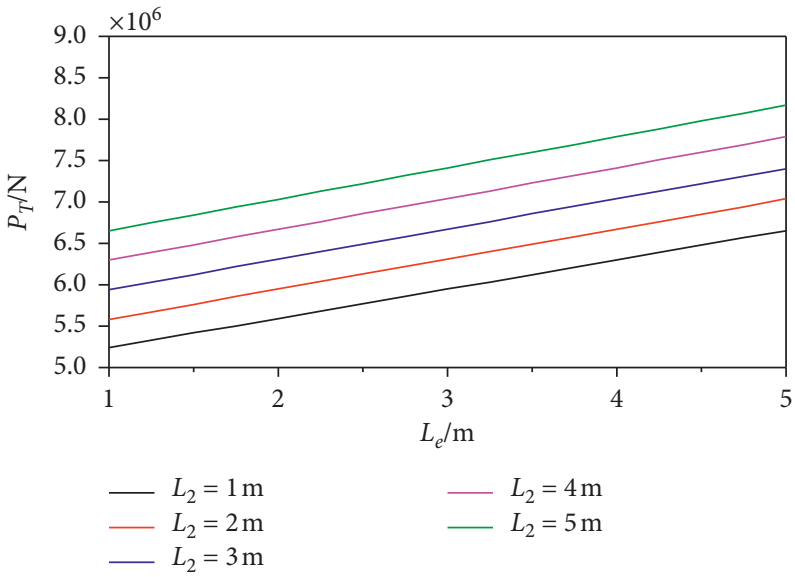

Figure 8: Relation between $P_{T}$ and $L_{e}$ with different $L_{2}$.

the changing trend is also similar to the numerical, as shown in Figure 6.

As shown in Table 1, when the distance of the PARs and the face is $8 \mathrm{~m} \sim 11 \mathrm{~m}$, the value of support capacity of shield is at a lower level, which means the panel face is in Stage I of the process of passing through the PARs. When the distance of the PARs and the face is $3 \mathrm{~m} \sim 6 \mathrm{~m}$, the support capacity of shield is at a peak value, which means the panel face is in 
TABLE 1: Support capacity of No.15 shields changes.

Serial number of PAR

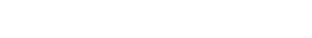

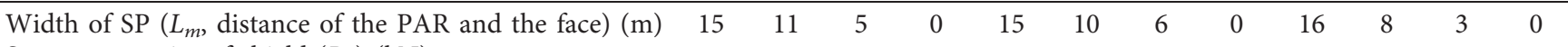

Support capacity of shield $\left(P_{T}\right)(\mathrm{kN})$

\begin{tabular}{llllllllllll}
5728 & 3853 & 5220 & 2702 & 5798 & 4935 & 6332 & 3354 & 5696 & 3876 & 5479 & 2941 \\
\hline
\end{tabular}

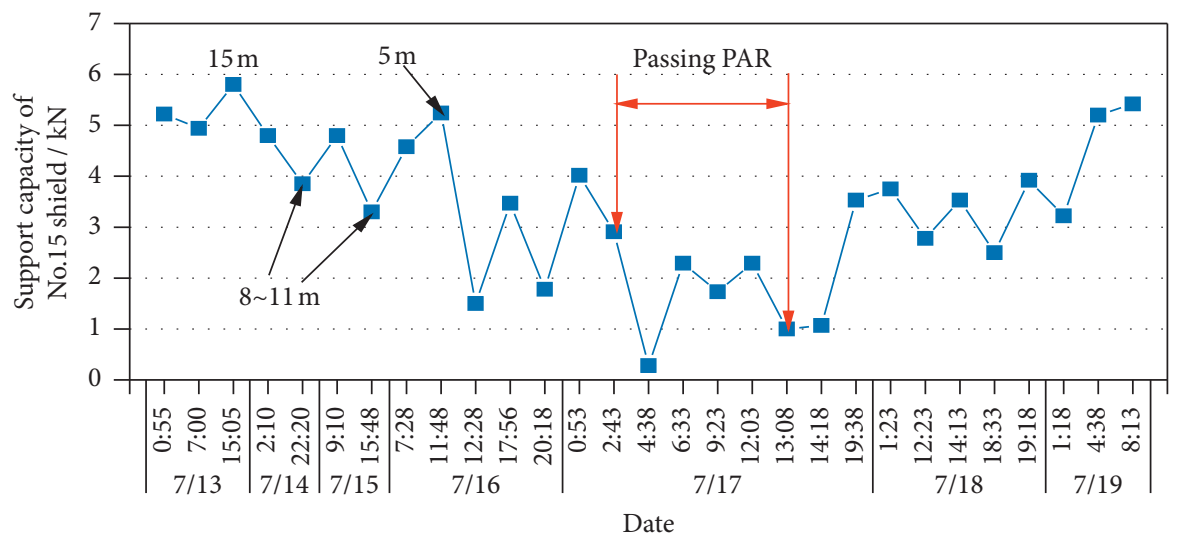

(a)

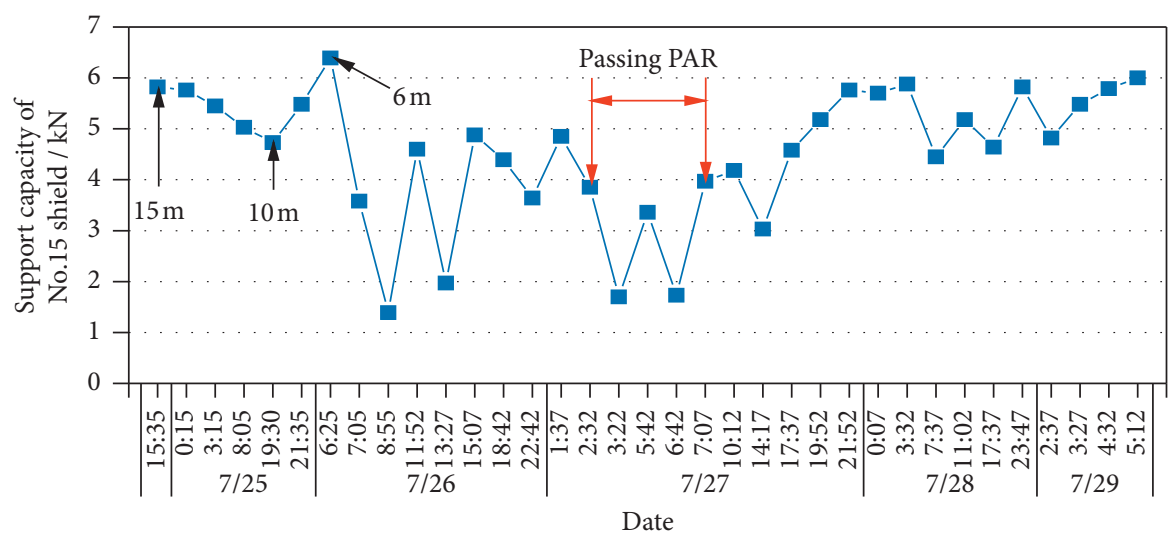

(b)

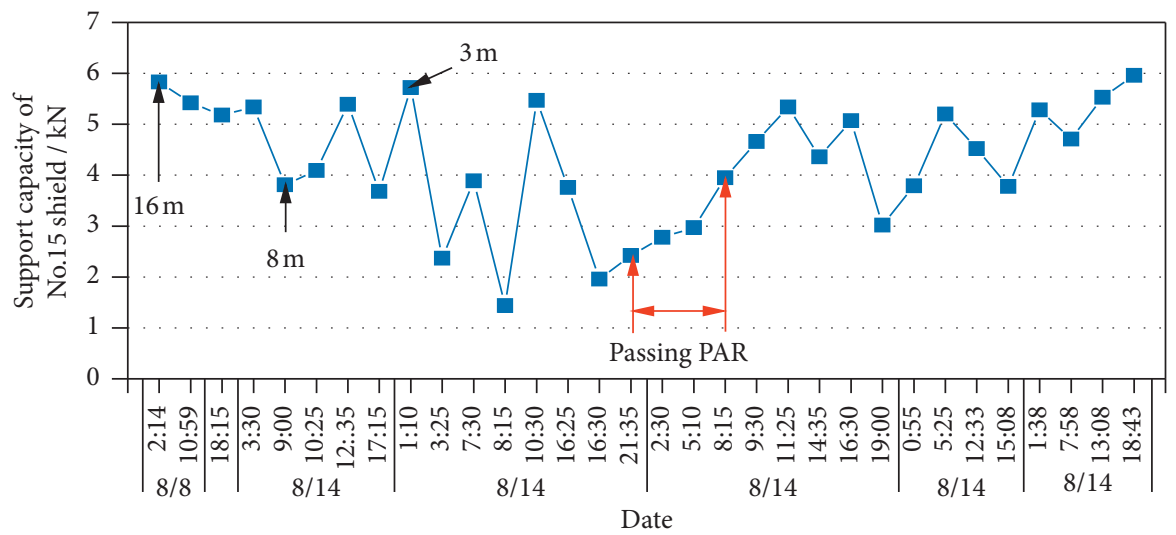

(c)

Figure 9: Support capacity of No. 15 shield changes during passing the PARs. (a) Passing the first PAR. (b) Passing the second PAR. (c) Passing the third PAR. 
Stage II of the process of passing through the PARs. When the distance of the PARs and the face is less than $3 \mathrm{~m}$, the value of the support capacity of shield decreases until the PARs exposes, which means the face is in Stage III of the process of passing through the PARs.

Besides, the support capacity of shield is at a low level when the "swing-inclined" mining method is adopted for the longwall panel face passing through the PARs. It is conducive to reduce the accident of roof falling, coal wall spalling, and crush accident of the shield. It is helpful for the longwall panel face to pass the PARs.

\section{Conclusions}

Based on the process of passing through the PARs of the E13103 panel in the Cuijiazhai coal mine, a new method named the "swing-inclined" mining method was proposed. The procedure of the "swing-inclined" mining method was described. A theoretical analysis was performed to study the relation of shield-roof, and the sensitivity analysis of the influence factors of support capacity of shield was also studied. The following conclusions can be drawn.

By establishing a long-span and multisupport massstructure-model of the roof when the panel face passes through the PARs, the calculation formula of the support capacity of shield is obtained, according to the stability relation between the "roof-support-PAR-SP-coal wall." And, the influence factors of support capacity of shield about distance are also obtained, including the hanging distance of the main roof $\left(L_{X}\right)$, the width of PAR $\left(L_{e}\right)$, the width of SP $\left(L_{m}\right)$, and the horizontal distance between the support point of coal wall and the breaking position of the main roof $\left(L_{2}\right)$.

The sensitivity analysis of the influence factors of support capacity of shield is performed by the Matlab software. The support capacity of shield decreases first and then increases with the hanging distance of the main roof $\left(L_{X}\right)$ increasing. According to the relation between the support capacity of shield $\left(P_{T}\right)$ and width of SP $\left(L_{m}\right)$, the process of passing through the PARs can be divided into 3 stages. And, in different stages, the changes in support capacity of shields are different. In Stage I and Stage III, the support capacity of shield $\left(P_{T}\right)$ decreases with the width of SP $\left(L_{m}\right)$ decreasing. However, in Stage II, the support capacity of shield $\left(P_{T}\right)$ increases with the width of SP $\left(L_{m}\right)$ decreasing. The support capacity of shield $\left(P_{T}\right)$ all increases linearly with the width of $\operatorname{PAR}\left(L_{e}\right)$ increasing. However, the increasing rates of support capacity of shield are different in different stages. The support capacity of shield $\left(P_{T}\right)$ increases with the horizontal distance between the support point of the coal wall and the breaking position of the main roof $\left(L_{2}\right)$ increasing. Therefore, it is necessary to employ some effective methods to control the mining pressure behavior. Thus, the support capacity of shield can be reasonably determined when the longwall panel face passes through PARs.

By on-site measurement, the changes in the support capacity of shield in the process of passing through the PARs are obtained. According to the observed data, it is verified that there are 3 stages in the process of passing through the PARs. And, the sensitivity analysis is verified by field measurement.

\section{Data Availability}

The data used to support the findings of this study are included within the article.

\section{Conflicts of Interest}

The authors declare that they have no conflicts of interest.

\section{Authors' Contributions}

All authors contributed equally.

\section{Acknowledgments}

This study was funded by the National Natural Science Foundation of China (no. 52074293), National Key R\&D Program of China (no. 2017YFC060300204), and Yue Qi Young Scholar Project, CUMTB, and the Yue Qi Distinguished Scholar Project (no. 800015Z1138).

\section{References}

[1] G. R. Feng, Study on the Theory and its Application of Upward Mining of Left-Over Coal, China Coal Industry Publishing House, Beijing, China, 2010.

[2] Y. Zhang, G. Feng, M. Zhang et al., "Residual coal exploitation and its impact on sustainable development of the coal industry in China," Energy Policy, vol. 96, pp. 534-541, 2016.

[3] G. R. Feng, Y. J. Zhang, T. Y. Qi et al., "Status and research progress for residual coal mining in China," Journal of China Coal Society, vol. 45, no. 1, pp. 151-159, 2020.

[4] Y. Li, M. Lei, H. Wang et al., "Abutment pressure distribution for longwall face mining through abandoned roadways," International Journal of Mining Science and Technology, vol. 29, no. 1, pp. 59-64, 2019.

[5] Y. Li, Y. Ren, S. S. Peng, H. Cheng, N. Wang, and J. Luo, "Measurement of overburden failure zones in close-multiple coal seams mining," International Journal of Mining Science and Technology, vol. 31, no. 1, pp. 43-50, 2021.

[6] X. Q. Zhang, Test and Study on Resource Recycle in Left-Over Areas of Thick Coal Seams, Taiyuan University of Technology, Taiyuan, China, 2011.

[7] X. X. Zhai, M. G. Qian, H. M. Li, and Y. Li, "Characteristics of plastic zone of second mining pillar and support technology of gateway in small mines," Chinese Journal of Rock Mechanics and Engineering, vol. 23, no. 22, pp. 3799-3802, 2004.

[8] J. C. Wang, "Sustainable coal mining based on mining ground control," Journal of Mining and Strata Control Engineering, vol. 1, no. 2, pp. 40-47, 2019.

[9] D.-z. Kong, W. Jiang, Y. Chen, Z.-y. Song, and Z. Ma, "Study of roof stability of the end of working face in upward longwall top coal," Arabian Journal of Geosciences, vol. 10, no. 8, p. 185, 2017.

[10] M. H. Xu, Surrounding Rock Control and Security Technology Research on Old Residual Coal Mining Longwall Minin, Taiyuan University of Technology, Taiyuan, China, 2012.

[11] Y. Li, "Overburden movement in solid waste rock cemented backfill mining methods," Journal of China Coal Society, vol. 9, pp. 370-374, 2011.

[12] Y. Li, "Groundwater system for the periods of pre-and postlongwall mining over thin overburden," International Journal 
of Mining, Reclamation and Environment, vol. 30, no. 4, pp. 298-311, 2016.

[13] J. Guo, G. Feng, P. Wang, T. Qi, X. Zhang, and Y. Yan, "Roof strata behavior and support resistance determination for ultra-thick longwall top coal caving panel: a case study of the Tashan coal mine," Energies, vol. 11, no. 5, p. 1041, 2018.

[14] J. C. Wang and Z. H. Wang, "Stability of main roof structure during the first weighting in shallow high-intensity mining face with thin bedrock," Journal of Mining and Safety Engineering, vol. 32, no. 2, pp. 175-181, 2015.

[15] H. W. Wang, Y. D. Jiang, B. P. Deng et al., "Study of stress state of coal pillar in failure zone of coal seam under dynamic pressure of mining," Chinese Journal of Rock Mechanics and Engineering, vol. 33, no. 10, pp. 2056-2063, 2014.

[16] X. Q. Zhang, P. L. Gong, K. Wang et al., "Characteristic and mechanism of roof fracture ahead of the face in an LTCC panel when passing an abandoned roadway: a case study from the Shenghua coal mine, China," Rock Mechanics and Rock Engineering, vol. 52, no. 8, pp. 2775-2788, 2019.

[17] C. Liu, P. L. Gong, K. Wang et al., "Roof stability for repeated mining workface passing through abandoned parallel gateway," Journal of China Coal Society, vol. 40, no. 2, pp. 314-322, 2015.

[18] C. Liu, J. W. Zhang, Z. Q. Yang et al., "Mechanism of advance fracture of main roof and its control technology when workface crossing abandoned roadway," Rock and Soil Mechanics, vol. 39, no. 4, pp. 1411-1421, 2018.

[19] K. K. Du, Research on the Technology of Waiting Pressure When Passing Through Abandoned Roadway in Fully-Mechanized Face With Annual Coal Production of 10 Million Tons, Shandong University of Science and Technology, Qingdao, China, 2011.

[20] S. R. Xie, S. J. Li, Z. Wei et al., "Stability control of supportsurrounding rock system during fully mechanized caving face crossing abandoned gateroad period," Journal of China Coal Society, vol. 40, no. 3, pp. 502-508, 2015.

[21] Q. Y. Xu, Z. X. Ning, R. S. Zhu et al., "Study on the instability mechanism and top control overfilled roof in fully mechanized caving face," Journal of Mining and Safety Engineering, vol. 36, no. 3, pp. 502-512, 2019.

[22] C. Liu, Z. Yang, P. Gong et al., "Accident analysis in relation to main roof structure when longwall face advances toward a roadway: a case study," Advances in Civil Engineering, vol. 2018, Article ID 3810315, 11 pages, 2018.

[23] C. Y. Yin, G. M. Feng, P. Gao, and Y. Zhao, "Research on instability mechanism of surrounding rock in stage of working face passing abandoned roadway," Journal of Mining and Safety Engineering, vol. 35, no. 3, pp. 457-464, 2018.

[24] Y. Du, G. Feng, Y. Zhang, X. Zhang, Y. Zhai, and J. Bai, "Pressure reduction mechanism and effect of working face passing through abandoned roadway by roof presplit," Energy Science \& Engineering, vol. 8, no. 10, pp. 3502-3513, 2020.

[25] Y. Li, E. G. Zhu, K. N. Zhang et al., "Mining methods and roof caving mechanism in long wall mining through the abandoned gateroads of small mines," Journal of China Coal Society, vol. 42, no. S1, pp. 16-23, 2017.

[26] E. G. Zhu, Study on Stability of Surrounding Rock and Support during Adjustment and Overpassing of Empty Face in Working Face, China University of Mining and Technology, Beijing, China, 2018.

[27] G. Jia and P. L. Gong, "Stability of surrounding rock when long-wall working face passing oblique crossing abandoned tunnel," Shanxi Coal, vol. 35, no. 4, pp. 32-35+43, 2015.
[28] J. C. Wang, "Mechanism of the rib spalling and the controlling in the very soft coal seam," Journal of China Coal Society, vol. 32, no. 8, pp. 785-788, 2007.

[29] B. P. Deng, Investigation on Repeated Mining Technology of Failure Zone in Xinliu Coal Mine, China University of Mining and Technology, Beijing, China, 2013.

[30] S. C. Gu, B. N. Wang, R. B. Huang, and Y. Miao, "Method for determining the load on and width of coal pillar at the recovery room end of fully-mechanized longwall mining," Journal of China University of Mining and Technology, vol. 44, no. 6, pp. 990-995, 2015.

[31] Y. Li and S. S. Peng, "Groundwater above the longwall panel in shallow coal seams," Journal of Rock Mechanics and Geotechnical Engineering, vol. 7, no. 3, pp. 298-305, 2015.

[32] G. R. Feng, J. W. Bai, X. D. Shi et al., "Key pillar theory in the chain failure of residual coal pillars and its application prospect," Journal of China Coal Society, vol. 46, no. 1, pp. 164-179, 2021.

[33] J. W. Bai, B. Q. Cui, T. Y. Qi et al., "Fundamental theory for rock strata control of key pillar-side backfilling," Journal of China Coal Society, vol. 46, no. 2, pp. 424-438, 2021.

[34] Y. Ren, G. Feng, P. Wang et al., "Vertical stress and deformation characteristics of roadside backfilling body in gob-side entry for thick coal seams with different pre-split angles," Energies, vol. 12, no. 7, p. 1316, 2019. 